\title{
A meta-analysis of projected global food demand and population at risk of hunger for the period 2010-2050
}

\author{
Michiel van Dijk ${ }^{1,2} \bowtie$, Tom Morley ${ }^{1}$, Marie Luise Rau' and Yashar Saghai ${ }^{3,4}$
}

Quantified global scenarios and projections are used to assess long-term future global food security under a range of socio-economic and climate change scenarios. Here, we conducted a systematic literature review and meta-analysis to assess the range of future global food security projections to $\mathbf{2 0 5 0}$. We reviewed $\mathbf{5 7}$ global food security projection and quantitative scenario studies that have been published in the past two decades and discussed the methods, underlying drivers, indicators and projections. Across five representative scenarios that span divergent but plausible socio-economic futures, the total global food demand is expected to increase by $35 \%$ to $56 \%$ between 2010 and 2050, while population at risk of hunger is expected to change by $-91 \%$ to $+\mathbf{8} \%$ over the same period. If climate change is taken into account, the ranges change slightly ( $+30 \%$ to $+62 \%$ for total food demand and $-91 \%$ to $+30 \%$ for population at risk of hunger) but with no statistical differences overall. The results of our review can be used to benchmark new global food security projections and quantitative scenario studies and inform policy analysis and the public debate on the future of food.

he question of how to eradicate global hunger-one of the Sustainable Development Goals_-and feed the future world population is a major global societal challenge. To support the formulation of effective policies to ensure global food security, a better understanding of the range of future outcomes and main driving forces is needed. Global assessments have mainly used four broad indicators to measure the various dimensions of food (in) security: food demand ${ }^{1,2}$, population at risk of hunger ${ }^{3,4}$, food prices and childhood undernutrition ${ }^{6}$. Often, the results of these studies vary widely and are difficult to compare because of differences in methods ${ }^{7}$, assumptions on driving forces ${ }^{8}$ and definitions of output indicators ${ }^{9}$. To date, no comprehensive analyses of global food security projections have been presented. The aim of this paper is to provide a review of recent global food security projection and quantitative scenario studies that provide trends to 2050. Collecting and comparing quantitative scenario results to assess model uncertainty has been a common practice in the climate change literature $^{10}$ but has not been done for global food security assessments. The main question addressed in this review is: what is the range of future global food security projections to 2050? To answer this question and to better understand why projections differ, we also review the methods and indicators that have been used in the modelling studies.

We applied a systematic literature review approach to identify and collect relevant studies that were published between 2000 and early 2018 , followed by a meta-analysis to assess the range of global food security projections for the period 2010-2050. We identified and analysed 57 relevant studies and constructed a database with harmonized projections for two of the four global food security indicators used in the literature: global food demand (593 projections) and global population at risk of hunger (358 projections), representing a wide range of plausible socio-economic and climate change futures.
Results

Overview of studies. We selected 57 global food security projection studies for further review using a predetermined systematic review protocol (Extended Data Fig. 1, Supplementary Information and Methods). Figure 1 shows that the number of studies increased substantially over the past two decades. The increase in publications after 2009 can almost certainly be attributed to the renewed interest in global food and nutrition research that was triggered by the 2007-2008 global food price crisis ${ }^{11}$. In recent years, there has been a transition from single-model studies to multi-model comparisons that present and discuss the results of an ensemble of models. Many of these studies are produced as part of the Agricultural Model Intercomparison and Improvement Project ${ }^{12}$.

Three different methods have been used to assess future global food security (Fig. 2a). The majority of studies $(n=47)$ employ simulation models, while some use statistical extrapolation approaches $(n=9)$ that use regression techniques to estimate future food security ${ }^{1,13}$. Only one study ${ }^{2}$ mainly used expert input to prepare the projections. The IMPACT model ${ }^{14}$ was the most frequently used simulation model $(n=16$, Fig. $2 \mathrm{~b})$. This is not surprising, as it was already developed in the early 1990s by the International Food Policy Research Institute (IFPRI) to analyse long-term hunger and poverty challenges. The set of models that form the core of the global assessment component of the Agricultural Model Intercomparison and Improvement Project are also often applied in global food security assessments. Apart from the IMPACT model, these include GLOBIOM ${ }^{15}$, MAGNET ${ }^{16}$, AIM/ $\mathrm{CGE}^{17}, \mathrm{IMAGE}^{18}$ and MAgPIE ${ }^{19}$. Other often-applied models are SIMPLE $^{20}, \mathrm{BLS}^{3}$ and ENVISAGE ${ }^{21}$. The most frequently used type of models is partial equilibrium models $(n=42)$, followed by computable general equilibrium market simulation models $(n=28)$ and other types of models (such as integrated assessment, biophysical and economic; $n=11)$.

'Wageningen Economic Research, the Hague, the Netherlands. ${ }^{2}$ International Institute for Applied Systems Analysis, Laxenburg, Austria. ${ }^{3}$ University of Twente, Enschede, the Netherlands. ${ }^{4}$ The Millennium Project Global Futures Studies and Research, Washington DC, USA. ${ }^{\mathrm{e} e-m a i l: ~ m i c h i e l . v a n d i j k @ w u r . n l ~}$ 


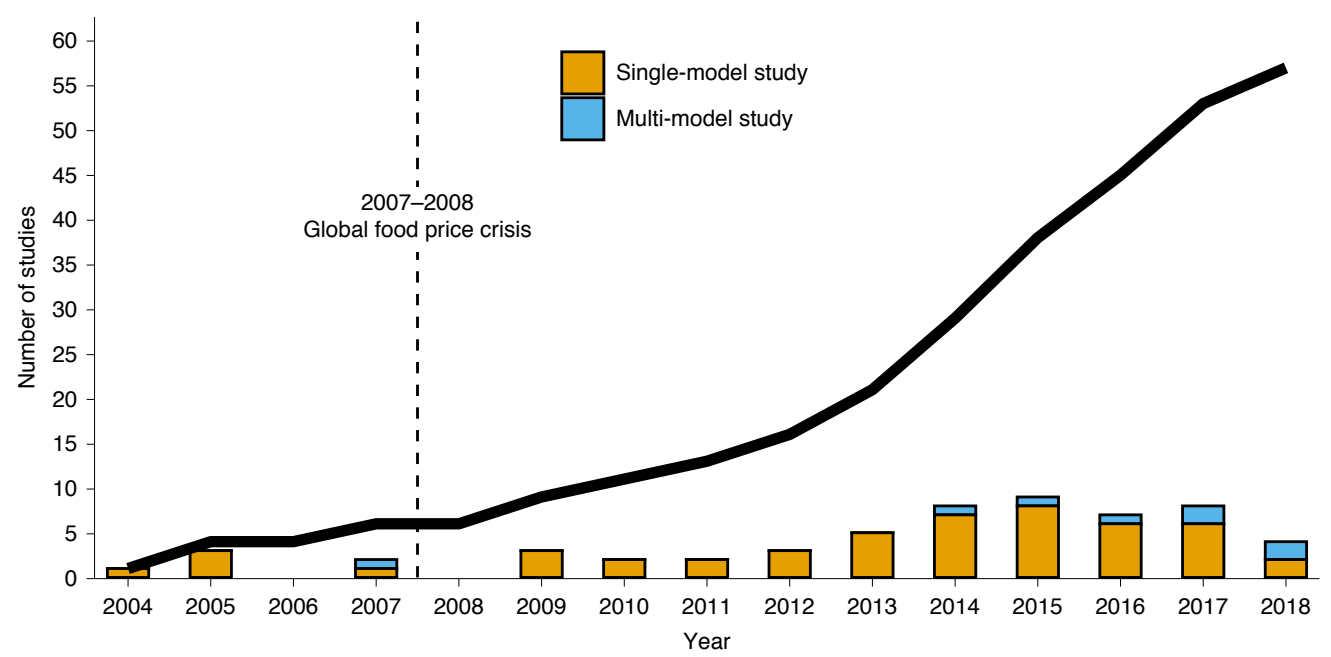

Fig. 1 | Total (cumulative) number and types of global food security studies per year. The bars show the publication of new studies per year and the types of studies published. The data for 2018 are incomplete as they only include studies that were released in the first half of the year.

Global food security is a complex issue that is determined by the interaction of a multitude of driving forces that operate on both the demand and supply sides. Nearly all studies include assumptions on future population $(n=57)$ and income growth $(n=52)$, which are key drivers of food demand, and assumptions on technical change (including total factor productivity growth, crop yield increase and adoption of advanced inputs) ( $n=52)$, which is the main driver of food supply (Fig. 2c). Other drivers that are covered by more than half of the studies include land availability (such as protected areas and land degradation) $(n=41)$, diet change $(n=39)$, trade $(n=37)$ and climate change $(n=32)$. Only a very small number of studies indicate that they explicitly address the impacts of aquaculture $(n=2)^{22,23}$ and urbanization $(n=1)^{23}$ on global food supply and demand projections.

A large number of the selected studies present future trends for two indicators (Fig. 2d). The first is per capita food demand, in most cases measured as the average diet per person (sum of crops, dairy, fish and meat in kcal per capita per day) $(n=37)$. The second indicator is global population at risk of hunger $(n=21)$, which implements the prevalence of undernourishment-the main statistic used by the Food and Agriculture Organization (FAO) to measure the number of hungry people ${ }^{24}$-in a forward-looking framework. Food price $(n=18)$ and, to a lesser extent, childhood undernutrition $(n=7)$ are other popular indicators. A few studies $(n=8)$ present alternative indicators, including protein consumption $^{25,26}$, people at risk of protein deficiency ${ }^{27}$ and recommended daily intake of macronutrients ${ }^{26}$. Shutes et al. ${ }^{28}$ build on a set of historical food security indicators prepared by the FAO (for example, share of calories from cereals, fruit and vegetables) to assess future global food security.

Projections of global food demand and population at risk of hunger. The distribution of food security outcomes within and between studies is determined by the combination of (1) varying assumptions on key drivers, often related to a scenario storyline on how the future might unfold, and (2) differences in method, such as the type and parameterization of the model and how the results are reported. To unravel these two factors, we mapped all projections to the Shared Socio-economic Pathways (SSPs; see Extended Data Fig. 2 for a summary of these scenarios) and the Representative Concentration Pathways (RCPs), a combination of socio-economic and climate change scenarios ${ }^{29-32}$, which are frequently used in global assessments ${ }^{33,34}$. For a subset of the selected studies, we were able to extract and harmonize projections for the two most used indicators: per capita demand $(n=21)$ and population at risk of hunger $(n=14)$.

Figure 3 presents two indicators for the future trends in food demand: change in per capita consumption (in kcal per capita per day) and change in total food consumption (in $1 \times 10^{15} \mathrm{kcal}$ ). The latter captures the combined impact of changes in the diet and growth in population (Extended Data Fig. 3). Nearly all SSP scenarios project an increase in per capita and global food consumption in comparison with the 2010 levels, but the relative sizes of these increases differ. In future worlds that are characterized by fragmentation (SSP3) and inequality (SSP4), per capita consumption will increase by $4 \%$ to $7 \%$, while in scenarios that assume sustainability (SSP1), business-as-usual development (SSP2) and rapid growth (SSP5), the increase is $12 \%$ to $16 \%$. Taking population growth into account, total food consumption increase is the lowest in SSP1 (+41\%) and the highest in SSP2 $(+51 \%)$.

The distribution of projections within each SSP illustrates the uncertainty caused by methodological differences between studies. The figure shows that the results of several studies can be considered as less plausible because they are located outside the $95 \%$ confidence interval. If the confidence band of all SSPs is jointly taken into account, the plausible bandwidth of per capita food consumption becomes $+0 \%$ to $+20 \%$ and of total food consumption becomes $+35 \%$ to $+56 \%$. Figure 3 also compares the results between no climate change (NOCC) and extreme climate change (RCP8.5) scenarios (see Extended Data Fig. 4 for a comparison with a wider range of RCPs). If the uncertainty related to climate change is also taken into account, the ranges of per capita $(-1 \%$ to $+20 \%)$ and total food demand $(+30 \%$ to $+62 \%)$ projections change slightly. However, a pairwise comparison did not provide evidence that climate change results in significantly different patterns of food demand compared with NOCC (Supplementary Fig. 7).

Figure 4 depicts the projections for population at risk of hunger. Nearly all projections point to a decrease in undernourishment in comparison with the base year. The change is highest in SSP1 and SSP 5 , with NOCC point estimates of $-71 \%$ to $-68 \%$, while it is smallest in SSP3 (-11\%), and SSP2 and SSP4 are located in the middle $(-57 \%$ to $-17 \%)$. If the $95 \%$ confidence interval is considered, the projected change in population at risk of hunger lies between $-91 \%$ and $+8 \%$ for NOCC projections and between $-91 \%$ and 
a

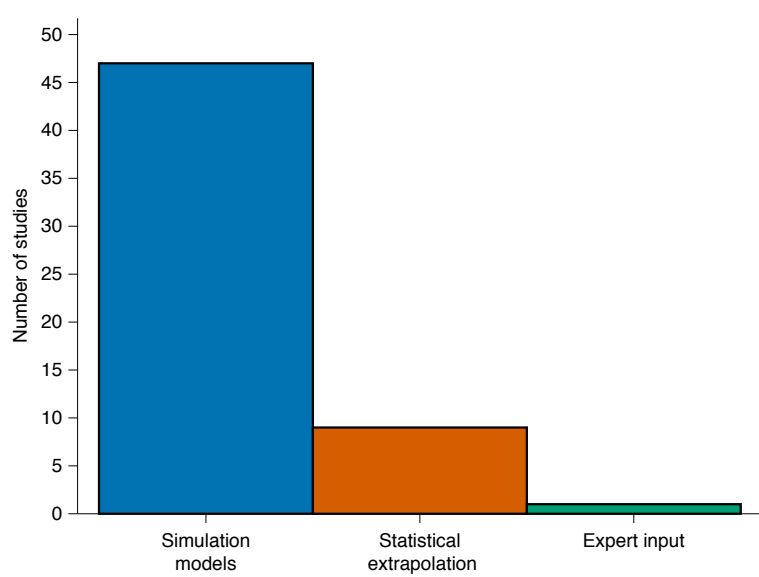

c

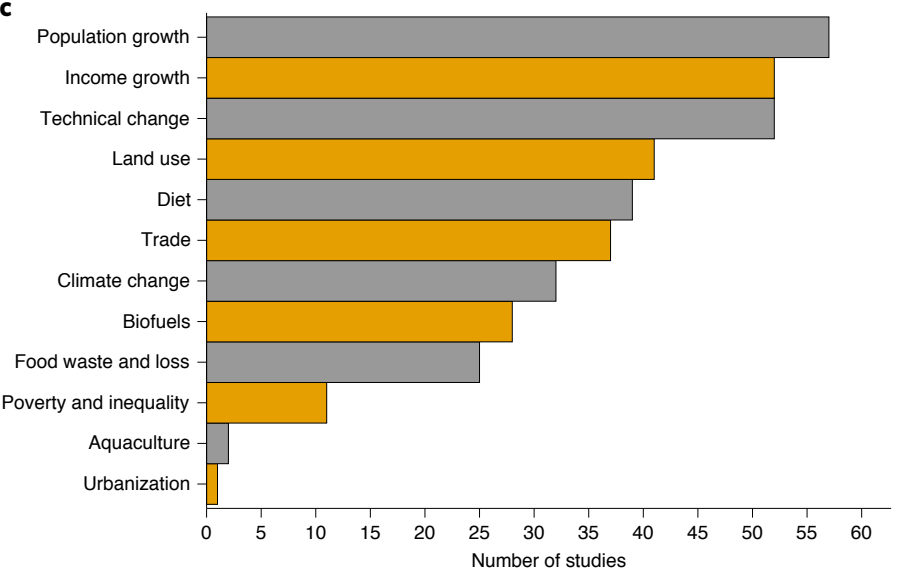

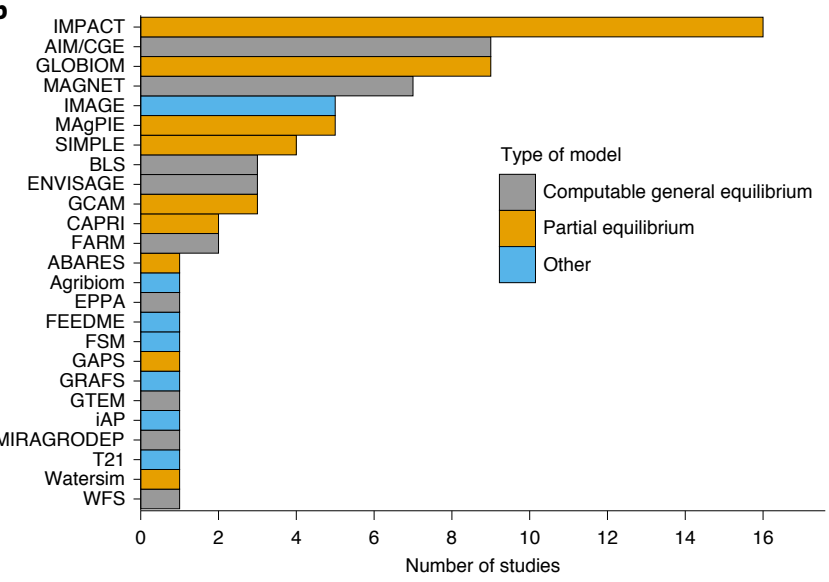

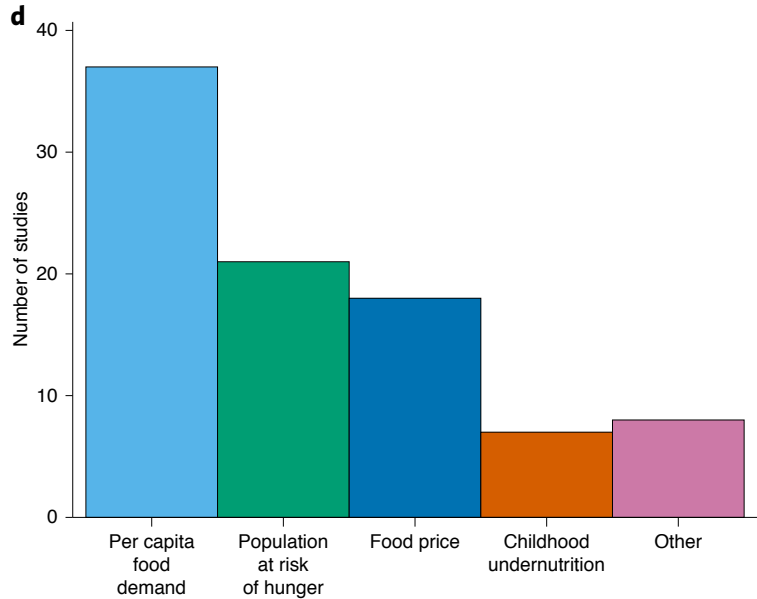

Fig. 2 | Methods, drivers and food security indicators of the selected studies. a, Main methods. b, List of simulation models. The 'Other' model type category includes biophysical, econometric and integrated assessment models. c, Drivers. d, Food security indicators. All studies incorporate multiple drivers and can produce multiple indicators. See the text for a description of 'Other' indicators.

$+30 \%$ for climate change projections (Extended Data Fig. 5). Again, we did not find evidence that climate change projections are statistically different from NOCC projections (Supplementary Fig. 7).

\section{Discussion}

Comparison with the prevailing discourse on future global food demand. The expected increase in food production and associated impacts on land use change, biodiversity and climate change depend heavily on projections of global food demand and consumption. The most cited figure, originating from an FAO briefing paper ${ }^{35}$, states that world food production needs to increase by $70 \%$ to feed the world population in 2050. Although this number was reduced to $60 \%$ in a revision of the original study ${ }^{2}$, it continues to be used as a reference point by companies ${ }^{36}$ and scientific papers ${ }^{37}$. Another widely cited paper is Tilman et al. ${ }^{1}$, who present a much higher increase in global food demand of $100-110 \%$ between 2005 and 2050. Opponents of mainstream agriculture often dismiss global food future projections and scenarios because they believe that the cited $60-110 \%$ increase in food demand (or its doubling, for short) erroneously frames global food security as a problem of supply (or even scarcity), closing off discussions of solutions that do not principally rely on increasing food production through technological innovation. Such solutions include the adoption of food sovereignty principles (for example, agro-ecological approaches that stress the value of indigenous knowledge, culture and peasant autonomy) as well as radical non-market-driven changes in diets ${ }^{38-40}$.
How do the $+60 \%$ to $+110 \%$ figures compare to our findings? We find that under SSP2 (which, like the FAO projections, is regarded as a business-as-usual scenario), total food consumption will increase by $51 \%$, with a $95 \%$ confidence interval of $+45 \%$ to $+56 \%$. This is substantially lower than the $\mathrm{FAO}^{2}$ and Tilman et al. projections of $60-110 \%$.

There are at least two reasons for the difference ${ }^{41,42}$. The main reason is that the FAO trend is estimated using the earlier base year 2005/2007 and therefore overestimates the expected increase in food consumption in comparison with the 2010 base year that is used in our review. The second reason is that it measures food consumption in value terms using food prices as weights instead of the preferred calorie-based measure ${ }^{43}$. The value-term measure tends to overestimate food consumption in the case of a diet shift from low-price staples towards higher-value products that might have occurred since 2005/2007. Interestingly, the latest update of the FAO study ${ }^{2}$ also presents a projection of $54 \%$ for the global change in calories. Using a base year of 2010, this translates to an increase in consumption of $44 \%$, which is just outside the confidence interval for SSP2. This shows that the FAO projections are comparable to those of other studies, but the results are highly sensitive to the selection of the base year. Without mentioning the reference period, statements about future increases in food demand and production can be severely misleading.

The projections in Tilman et al. ${ }^{1}$ cannot easily be compared with most of the studies in our review because of differences in approach. 

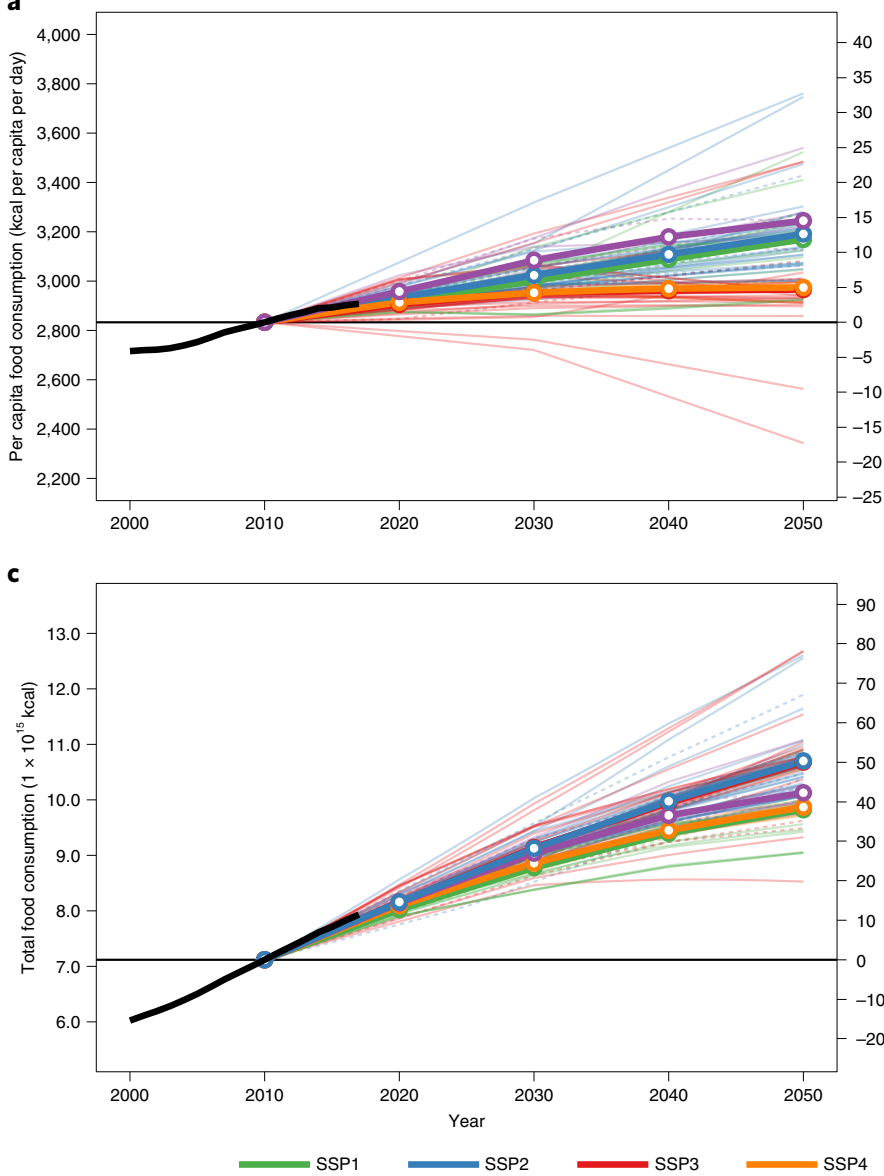

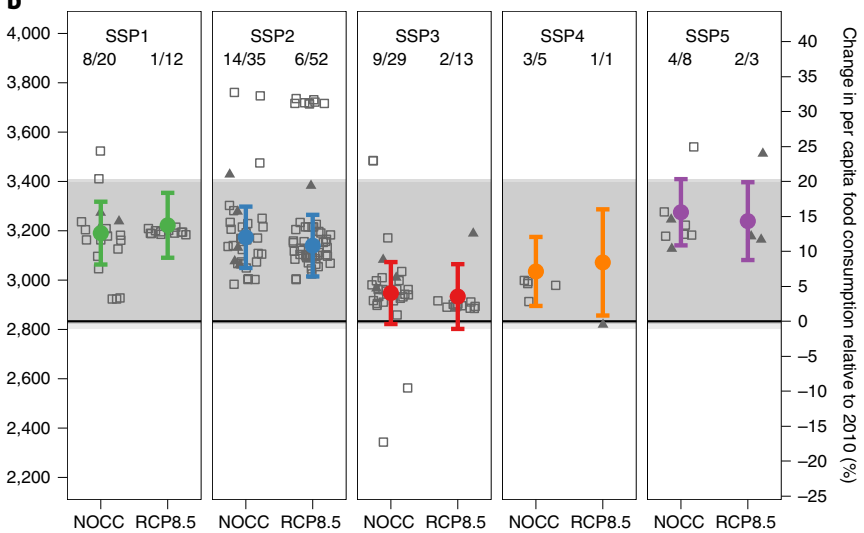

d

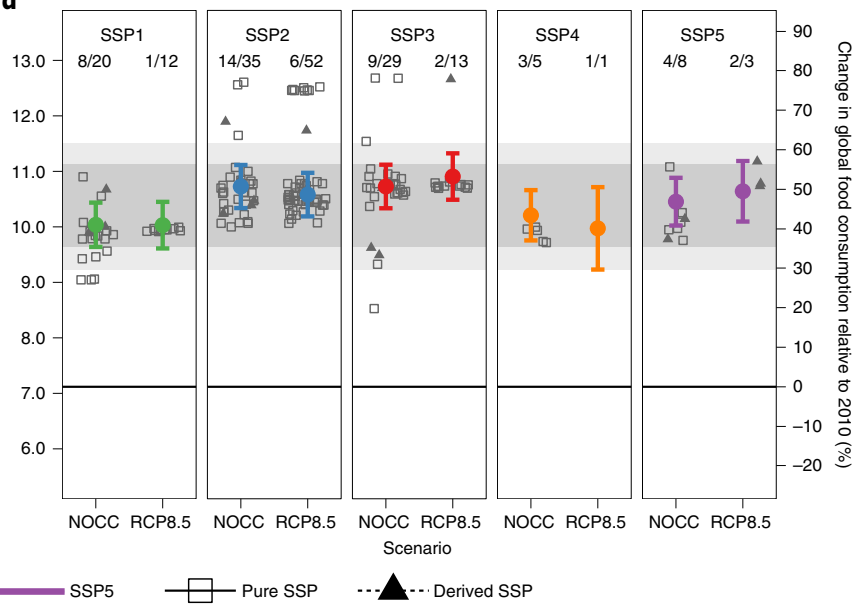

Fig. 3 | Per capita and total food consumption baseline projections for 2010-2050. a,b, Per capita food consumption baseline projections. c,d, Total food consumption baseline projections. All figures show the level of the selected food security indicator (left $y$ axis) and the percentage increase for the period 2010-2050 (right $y$ axis). Panels a and $\mathbf{c}$ show the baseline projections for the SSPs under NOCC (thin coloured lines), the average for each SSP (thick coloured lines with circles) and the three-year average historical trend (thick black line). Panels $\mathbf{b}$ and $\mathbf{d}$ present point estimates and $95 \%$ confidence intervals taken from the meta-regression as well as all observations in 2050, comparing NOCC projections with projections based on the most extreme climate scenario (RCP8.5). The numbers at the top refer to the number of studies/number of projections in the figure. The dark and light grey shaded areas demarcate the plausible range of baseline projections using the $95 \%$ confidence interval across all NOCC SSP and all RCP SSP projections, respectively (Extended Data Fig. 4). Pure SSPs are projections that take their assumptions from the SSPs, where relevant combined with RCP-based climate impact scenarios. Derived SSPs are projections that belong to the same SSP and RCP scenario families but use somewhat different assumptions. The historical data are from $\mathrm{FAO}^{70}$. The projections are from the Global Food Security Projections Database.

In contrast to most other studies, which use diet projections, food consumption is approximated by total crop calories (including food and feed), resulting in much higher per capita projections. The study implicitly assumes that food and feed have the same relationship with income per capita. This deviates from most model studies, which assume an increase in feed-to-food conversion efficiency rates $^{44}$ and hence a lower relative future demand for feed. Not accounting for potential efficiency improvements in the livestock sector might explain why the food consumption projections in Tilman et al. ${ }^{1}$ are nearly twice as large as those in most other studies.

Uncertainty and consistency in global food security projections. The 95\% confidence intervals of the point estimates show that there is a degree of uncertainty in the projections. Three factors may explain the high variation in observed food security outcomes ${ }^{9}$. First, in contrast to model comparison exercises ${ }^{45}$, where all models use harmonized assumptions on drivers and attempt to align the implementation of qualitative scenario assumptions, the input data of the studies in our review are not fully aligned despite our effort to map all projections to the SSP scenario framework. It seems that even 'pure' SSP studies use slightly different projections for core SSP building blocks, such as population growth, resulting in a variation of outcomes (Extended Data Fig. 3).

Second, differences in methods for modelling long-run global food security can strongly influence the results ${ }^{7,46}$. Systematic model comparisons showed that structural differences between assumptions on technological change $e^{47}$, the way food demand is modelled $^{48}$ and the type of model ${ }^{45}$ are important factors that explain differences in projections. Using our meta-regression, we formally tested the impact of model type on global food security projections but did not find convincing evidence to support this (Supplementary Section C).

Finally, differences in the way results are reported, such as differences in base year or definitions of indicators, potentially explain the wide range of outcomes. As one of the main aims of this study was to harmonize the food security projections to make them comparable, we do not expect this factor to be of major influence.

After all projections are harmonized and observations outside the $95 \%$ confidence interval (which can be considered as less plausible) are discarded, the projections are largely consistent. SSP1 and 

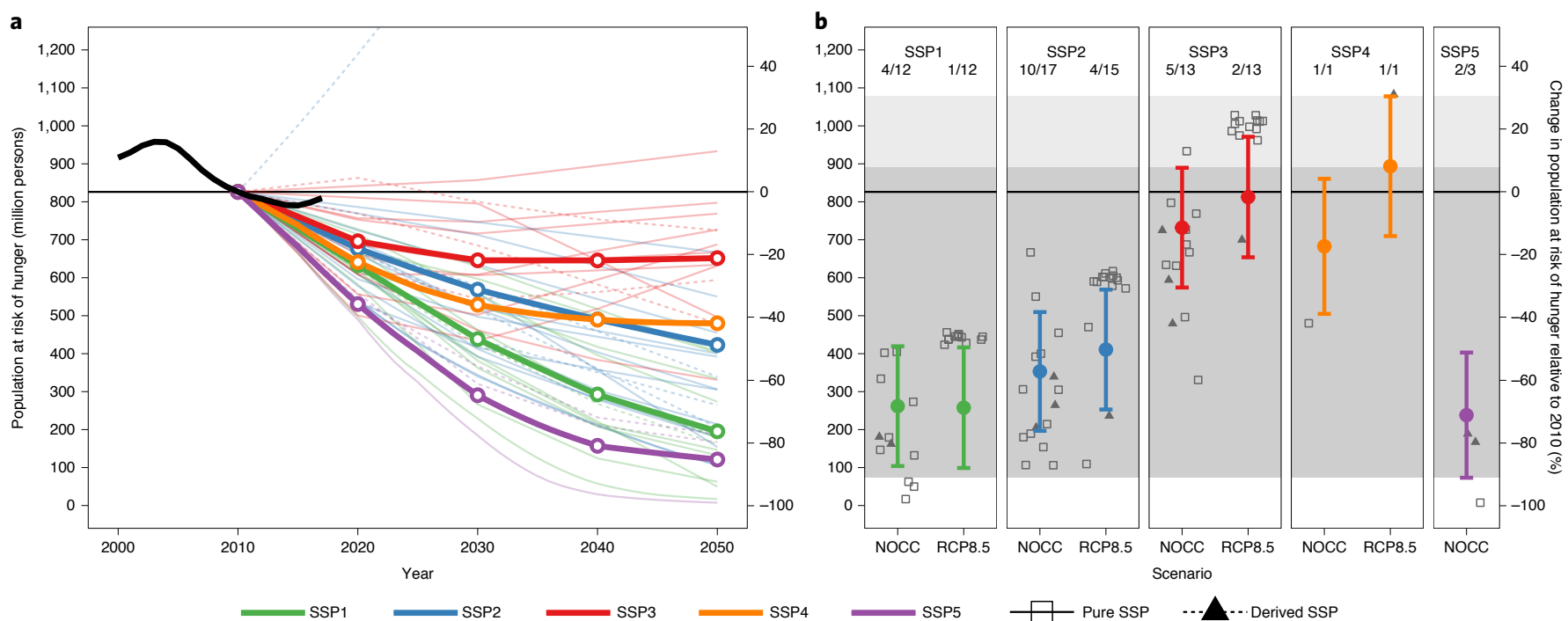

Fig. 4 | Population at risk of hunger baseline projections for 2010-2050. a, Baseline projections for the SSPs under NOCC (thin coloured lines), the average for each SSP (thick coloured lines with circles) and the three-year average historical trend (thick black line). b, Point estimates and $95 \%$ confidence intervals taken from the meta-regression as well as all observations in 2050, comparing NOCC projections with projections based on the most extreme climate scenario (RCP8.5). See Fig. 3 for a detailed explanation of the figure elements. The dark and light grey shaded areas demarcate the plausible range of baseline projections using the $95 \%$ confidence interval across all NOCC SSP and all RCP SSP projections, respectively (Extended Data Fig. 5). The projections from Dawson et al..$^{72}$ (the blue dashed line heading upwards in $\mathbf{a}$ ) are considered outliers and are therefore excluded from the meta-regression. The historical data are from $\mathrm{FAO}^{70}$. The projections are from the Global Food Security Projections Database.

SSP5 represent futures in which global food security will improve, reflected by a sharp decrease in population at risk of hunger, high levels of food consumption per capita and low total food consumption. SSP3 represents an opposite world, characterized by the highest population at risk of hunger, the lowest per capita consumption and the highest total food consumption. In most cases, the results for SSP2 and SSP4 are located in the middle of these extreme scenarios. The consistency of the SSPs is also supported by a pairwise comparison, which shows that the point estimates are statistically different for more than half of the SSP combinations (Supplementary Fig. 6).

Our findings indicate that, under NOCC, per capita and total food demand are expected to change by $+0 \%$ to $+20 \%$ and $+35 \%$ to $+56 \%$ between 2010 and 2050, respectively, while population at risk of hunger is projected to change by $-91 \%$ to $+8 \%$. Projections that account for climate change show a somewhat wider range of outcomes $(-1 \%$ to $+20 \%$ for per capita food demand, $+30 \%$ to $+62 \%$ for total food demand and $-91 \%$ to $+30 \%$ for population at risk of hunger). These figures reflect global food security outcomes in five vastly different but plausible future worlds with respect to sustainability, equality and technological development. We believe that these findings are more reflective of the current state of the literature than the often-cited range of $+60 \%$ to $+110 \%$ for food demand, which represents only business-as-usual scenarios.

Moreover, in the light of the current coronavirus pandemic, which undoubtedly will have a lasting impact on all aspects of future global development (including food supply and demand), business-as-usual scenarios can no longer be considered plausible or realistic. According to the World Food Programme, trade barriers put up by some countries to safeguard national food security in combination with an economic slowdown were expected to double acute hunger by the end of 2020 (ref. ${ }^{49}$ ). Although it is too early to understand the full impact and consequences of the coronavirus pandemic, current developments show some resemblance with the SSP3 Regional Rivalry scenario, which is characterized by slow economic development, a focus on domestic security and sovereignty, and increasing inequality within and between nations. The recent developments underscore the need for quantitative scenario analysis and comparison as a tool to inform policy analysis, coordination and planning for the future of food and wider societal issues.

\section{Methods}

Systematic literature review design. To select relevant studies on global food security projections, we followed the systematic review guidelines prepared by the EPPI-Centre (https://eppi.ioe.ac.uk; see ref. ${ }^{50}$ ). Our approach included five steps: (1) definition of research questions and preparation of research protocol, (2) search for relevant studies, (3) screening and selection of studies, (4) data extraction and (5) analysis. The core of the literature review was conducted between September and December 2017, but an additional search using the same approach was conducted around mid-2018 to cover the studies that were published in the first half of 2018. The main steps are summarized below. Additional details can be found in the review protocol (Supplementary Information).

We combined a number of search strategies to identify relevant studies: (1) we searched five electronic search engines of bibliographic databases (Scopus, Econlit, $\mathrm{CAB}$ abstracts, Agricola and Agris) using a combination of search terms; (2) we used Google Scholar, but only including the first two pages with references; (3) we consulted websites of organizations and institutions (for example, FAO, the Organisation for Economic Co-operation and Development, the World Bank and the International Food Policy Research Institute), which occasionally prepare global food security assessments; (4) we consulted experts working on the topic to inquire about relevant studies; and (5) we conducted a 'snowballing' exercise on all references from several global food security review studies, as these studies are assumed to bring together important literature.

The literature search generated a list of potentially relevant studies that were subsequently screened by applying a set of exclusion criteria. The query of the scientific literature repositories resulted in 3,667 unique studies. After abstract and full text screening, 57 studies were selected to be included in the systematic literature review (Extended Data Fig. 1; see Supplementary Section E for the list of studies). Finally, we used a questionnaire to systematically extract and code relevant information, including metadata, methods used, scenario information, food security indicators and main drivers. All data were stored in a database that is available for download.

Global Food Security Projections Database. For practical purposes, we decided to limit the collection and harmonization of data to two indicators that were presented in the majority of studies: per capita food consumption (in kcal per capita per day) and population at risk of hunger (in million persons). We also collected information on population projections to prepare total food consumption projections (in kcal). For a variety of reasons (Supplementary Section A.1), we were 
able to extract quantitative and comparable information on global food security projections from only $26(46 \%)$ of the 57 studies that resulted from the systematic literature review. All data were subsequently cleaned, harmonized and stored in a database (Supplementary Section A). The Global Food Security Projections Database contains 593 projections of food consumption per capita and total food consumption and 358 projections of population at risk of hunger.

To make the data comparable across studies and over time, we mapped the projections to the SSPs ${ }^{31,32}$. The SSPs were originally designed as a framework for the recent climate change assessments but have been increasingly used for the evaluation of other global challenges, including food security. Around $88-90 \%$ of the projections (Supplementary Fig. 4) already use the SSPs to produce food security projections. For all other projections, we built on Van Vuuren et al. ${ }^{51,52}$, who demonstrated that the assumptions of many global socio-economic scenarios (including the SSPs) are similar and can be classified into five archetypal scenario 'families. We assumed that projections based on the SSPs and projections based on scenarios with the same characteristics (that is, belonging to the same 'family') can be directly compared. However, as the assumptions underlying these scenarios are not exactly the same as those of the SSPs, we labelled them as derived SSPs. We used the tables in Van Vuuren et al. ${ }^{51,52}$ to map the majority of these projections to the SSPs. For all remaining studies, we added the mapping by comparing the storylines and directions of drivers with the description of the scenario families (Supplementary Table 1). We used a similar approach, drawing on Van Vuuren and Carter $^{52}$, to map all climate change projections to the RCPs (Supplementary Table 2). A small number of projections could not be mapped to one of the SSP scenario families. We labelled them as 'No class' and excluded them from further analysis but added them to the Global Food Security Projections Database fur further reference.

Finally, we divided the projections into 'baseline' and 'policy shock' projections (Supplementary Fig. 5). The first type is based on the assumptions of baseline scenarios, which assume that socio-economic development, including global food security, will be determined by future changes in the socio-economic driver (and associated major policy changes that can be regarded as exogenous to the analysis $)^{53}$. The SSPs are generally considered as baseline scenarios. The second type is used to investigate the impact of specific policies on global food security. This is usually done by comparing the results of a baseline projection with those of a policy shock projection. Their difference can be regarded as a measure of the potential policy impact ${ }^{54}$. For the meta-regression (see below), we used only the sample of baseline studies, which used the same or very similar assumptions and therefore could be harmonized and compared. The policy shock projections, in contrast, use widely different assumptions to model a large number of policies, which makes it hard to include them in the meta-regression. To analyse these projections, we grouped them by policy and compared the results with the estimated range that resulted from our meta-regression (Supplementary Fig. 8). The comparison shows that nearly all policy shock projections fall within the estimated bandwidth, confirming our main findings.

Meta-regression. After removing outliers and 'No class' projections (Supplementary Fig. 2), we conducted a meta-regression ${ }^{55}$ on the baseline projections to obtain point estimates for the percentage change in per capita consumption, total food consumption and population at risk of hunger for the period 2010-2050, taking into account differences between SSPs and RCPs. To control for the clustering of observations into groups (for example, projections conducted with the same model or harvested from the same study), we estimated separate linear mixed model ${ }^{56}$ for each of the three food security indicators:

$$
y_{i j}=\beta_{0}+\beta_{1} x_{1 i j}+\ldots+\beta_{p} x_{p i j}+b_{i 1} z_{1 i j}+\ldots+b_{i q} z_{q i j}+\varepsilon_{i j}
$$

where $y_{i j}$ is the $j$ th projection expressed as the percentage change between 2010 and 2050 in the $i$ th group; $\beta_{0}$ is the intercept; $\beta_{1}, \ldots, \beta_{p}$ are the fixed-effect coefficients; and $x_{1 i j}, \ldots, x_{p i j}$ are the fixed-effect regressors. We included fixed effects for all SSP-RCP combinations and dummy variables for pure (as opposed to derived) SSP and RCP scenarios. $b_{i}, \ldots, b_{i}$ are the random effects for group $i$, and $z_{1 j,} \ldots, z_{\text {i. }}$ are the random-effect regressors. We added random effects for both study and model as we assume that, although comparable, outcomes will vary across both studies and models because of differences in study design and model specifications. The projections in our sample can be regarded as random samples of all projections that could have been observed. Under these assumptions, a random effects model (as opposed to a fixed effects model) is recommended for meta-regression analysis ${ }^{55} . \epsilon_{i j}$ is the error for projection $j$ in group $i$.

The model was estimated using a restricted maximum-likelihood routine as implemented by the lme4 R package ${ }^{57}$ in combination with the lmerTest package ${ }^{58}$, which implements the Satterthwaite's degrees of freedom method for mixed models. The results of the model were used to derive point estimates and $95 \%$ confidence intervals based on standard errors for all SSP-RCP combinations for which data are available (Extended Data Figs. 4 and 5). The point estimates and confidence intervals were calculated by evaluating equation (1) at the population-weighted average values of the fixed effects and zero mean for the random effect variables using the $\mathrm{R}$ effects package ${ }^{59}$. We used the step-down strategy $y^{58,60,61}$ to select the model with the best fit. Independent variables, such as method, model base year and type of study, were dropped as a result of this procedure (Supplementary Section B). Point estimates for the percentage change were multiplied by the base year values to derive the level values for 2050 .

Selection bias. There is a risk that the results of our study were affected by selection bias. To account for publication bias, we conducted an extensive search for both academic and grey literature. Of the 57 studies, 18 (32\%) were unpublished at the time of our analysis. Additional estimations did not provide support for differences between projections from published and unpublished studies (Supplementary Table 5).

Another type of selection bias that potentially influenced our results is related to the fact that we were able to extract quantitative information from only a limited number of selected studies. This is not a problem by itself, as the mixed model we used for the meta-regression is designed to deal with data that represent a random sample of the total population. But in the case of non-random selection, the results of the meta-regression will be biased. A comparison of the main characteristics between studies for which quantitative data were extracted and those for which data were missing does not suggest major structural differences between these groups and hence does not provide evidence for selection bias (Supplementary Fig. 9). Where possible, we also compared the findings of these studies with the estimated SSP confidence bands from our meta-regression (Supplementary Tables 6 and 7). The strong overlap between the two provides additional evidence against the existence of selection bias in our analysed sample.

Finally, we investigated potential selection bias related to the 'No class' projections, which were excluded from the analysis because the underlying scenario assumptions were different from the SSP/RCP framework. A comparison shows that for all three indicators, almost all 'No class' projections fall within the estimated plausible range of global food security projections (Supplementary Fig. 10). Hence, excluding them probably had little impact on our results.

Limitations. To better interpret the results of our analysis, it is important to discuss a number of limitations. First, to summarize and compare the methods of the global food security studies, we distinguished between three major approaches (simulation models, statistical extrapolation and expert input), of which the first was further decomposed into computable general equilibrium, partial equilibrium and other models. In practice, this classification was not always straightforward. For example, a number of studies ${ }^{6,62}$ combine simulation modelling with statistical extrapolation to project future food security indicators. In several other studies, statistical approaches are used to estimate future food consumption, which is then used as an input into a larger simulation model. Examples of this approach are the $\mathrm{iAP}^{63}$ and MAgPIE models ${ }^{19}$. To be consistent, we decided to use the simulation models' category for all studies in which food security indicators are presented in the context or as part of a model simulation study, while stand-alone statistical approaches, even when they are used as part of a model in other studies ${ }^{13}$, were classified as 'statistical extrapolation'. Finally, in some studies, the models are linked with other models to deepen the analysis and cover a wider range of outcome indicators ${ }^{64}$ to enrich the analysis. In such cases, we assumed that the model is still comparable to its stand-alone version.

Second, the information on the drivers of global food security should be interpreted with care. Not all studies provide full details on the model specification and hence which drivers can be incorporated in the model. Occasionally, we took information on the incorporation of driving forces from other studies in which the same model was used.

Third, most of the high-ranking models used for global food security analysis (Fig. 2b) are (part of) large-scale integrated assessment tools that are used for global climate change ${ }^{65}$, biodiversity ${ }^{34}$ and land use ${ }^{66}$ studies, among others. Such models are continuously updated and expanded to respond to new research questions. The reviewed studies do not offer sufficient information to track changes in model design and input data from one study to the other. Nonetheless, we think it is reasonable to assume that the core of the models does not change over time and that cross-model comparison is possible.

Fourth, we were not able to map a small number of projections to the SSP/RCP framework because the underlying scenarios were not compatible with the SSP storylines and/or RCP climate change assumptions (Supplementary Section A.2). The SSPs cover only four of the six scenario families identified by Van Vuuren and Carter $^{52}$, which means that projections that belong to the two missing families (or even other not-yet-identified scenario families) are not captured by our analysis. A comparison shows that projections for missing scenario families are positioned within the plausible range of SSP/RCP-based global food security projections and therefore do not affect our results (Supplementary Fig. 10). If a sufficient number of projections from new scenario families become available, we can easily incorporate them in our assessment.

Finally, our analysis deals only with global-level projections. Several of the selected studies present food security projections at the broad regional level ${ }^{13,64,67}$ that clearly indicate different patterns and futures, which we are unable to analyse. We tried to collect comparable information at the regional level, but as only a smal number of studies cover and present such an analysis, and they often use different 
regional aggregations, a more disaggregated analysis was not feasible. For similar reasons, we were not able to distinguish between the demands for different food commodities. Only a few studies ${ }^{68,69}$ present detailed information on the shifts in diet, and in most cases the results are not comparable due to differences in the composition of food groups, making wider comparison impossible.

Reporting Summary. Further information on research design is available in the Nature Research Reporting Summary linked to this article.

\section{Data availability}

The core data used in the study were obtained from the selected studies (Supplementary Section E) including their supplementary information and data files. For a few studies, additional information was supplied by the authors upon request. Historical data for the selected food security indicators were taken from $\mathrm{FAO}^{70}$. The database with information from the 57 selected studies as well as the Global Food Security Projections Database are publicly available at the Zenodo repository: https://doi.org/10.5281/zenodo.4911252. A dashboard to visualize the projections is available at https://michielvandijk.shinyapps.io/gfsp_db_dashboard/.

\section{Code availability}

We used R (ref. ${ }^{71}$ ) for visualization and analysis. The complete code required to reproduce all figures as well as the meta-analysis is publicly available at the Zenodo repository: https://doi.org/10.5281/zenodo.4911251.

Received: 27 June 2020; Accepted: 16 June 2021;

Published online: 21 July 2021

\section{References}

1. Tilman, D., Balzer, C., Hill, J. \& Befort, B. L. Global food demand and the sustainable intensification of agriculture. Proc. Natl Acad. Sci. USA 108 20260 (2011).

2. Alexandratos, N. \& Bruinsma, J. World Agriculture Towards 2030/2050: The 2012 Revision (Food and Agriculture Organization of the United Nations, 2012)

3. Parry, M. L., Rosenzweig, C., Iglesias, A., Livermore, M. \& Fischer, G. Effects of climate change on global food production under SRES emissions and socio-economic scenarios. Glob. Environ. Change 14, 53-67 (2004).

4. Hasegawa, T., Fujimori, S., Takahashi, K. \& Masui, T. Scenarios for the risk of hunger in the twenty-first century using shared socioeconomic pathways. Environ. Res. Lett. 10, 014010 (2015).

5. Baldos, U. L. C. \& Hertel, T. W. Debunking the 'new normal': why world food prices are expected to resume their long run downward trend. Glob. Food Sec. 8, 27-38 (2016).

6. Ishida, H. et al. Global-scale projection and its sensitivity analysis of the health burden attributable to childhood undernutrition under the latest scenario framework for climate change research. Environ. Res. Lett. 9, 064014 (2014).

7. Godfray, H. C. J. \& Robinson, S. Contrasting approaches to projecting long-run global food security. Oxf. Rev. Econ. Policy 31, 26-44 (2015).

8. Reilly, M. \& Willenbockel, D. Managing uncertainty: a review of food system scenario analysis and modelling. Phil. Trans. R. Soc. B 365, 3049-3063 (2010)

9. van Dijk, M. \& Meijerink, G. A review of global food security scenario and assessment studies: results, gaps and research priorities. Glob. Food Sec. 3, 227-238 (2014).

10. Huppmann, D., Rogelj, J., Kriegler, E., Krey, V. \& Riahi, K. A new scenario resource for integrated $1.5^{\circ} \mathrm{C}$ research. Nat. Clim. Change https://doi. org/10.1038/s41558-018-0317-4 (2018).

11. Headey, D. \& Fan, S. Anatomy of a crisis: the causes and consequences of surging food prices. Agric. Econ. 39, 375-391 (2008).

12. Rosenzweig, C. et al. The Agricultural Model Intercomparison and Improvement Project (AgMIP): protocols and pilot studies. Agric. For. Meteorol. 170, 166-182 (2013).

13. Bodirsky, B. L. et al. Global food demand scenarios for the 21 st century. PLoS ONE 10, e0139201 (2015).

14. Robinson, S. et al. The International Model for Policy Analysis of Agricultural Commodities and Trade (IMPACT): Model Description for Version 3 (IFPRI, 2015); http://ssrn.com/abstract=2741234

15. Havlik, P. et al. Climate change mitigation through livestock system transitions. Proc. Natl Acad. Sci. USA 111, 3709-3714 (2014).

16. Woltjer, G. et al. The MAGNET Model Module Description (Wageningen Economic Research, 2014).

17. Fujimori, S., Hasegawa, T. \& Masui, T. in Post-2020 Climate Action (eds Fujimori, S. et al.) 305-328 (Springer Singapore, 2017); https://doi. org/10.1007/978-981-10-3869-3 13

18. Stehfest, E., van Vuuren, D. P., Bouwman, L. \& Kram, T. Integrated Assessment of Global Environmental Change with IMAGE 3.0: Model Description and Policy Applications (PBL Netherlands Environmental Assessment Agency, 2014).
19. Lotze-Campen, H. et al. Global food demand, productivity growth, and the scarcity of land and water resources: a spatially explicit mathematical programming approach. Agric. Econ. 39, 325-338 (2008).

20. Baldos, U. L. C. \& Hertel, T. W. Looking back to move forward on model validation: insights from a global model of agricultural land use. Environ. Res. Lett. 8, 034024 (2013).

21. van der Mensbrugghe, D. The ENVironmental Impact and Sustainability Applied General Equilibrium (ENVISAGE) Model (World Bank, 2008).

22. Linehan, V. et al. Global food production and prices to 2050: scenario analysis under policy assumptions. In 43rd ABARES Outlook Conference (2013).

23. The Future of Food and Agriculture-Alternative Pathways to 2050 (FAO, 2018).

24. FAO, IFAD, and WFP The State of Food Insecurity in the World: The Multiple Dimensions of Food Security 2013 (FAO, 2013).

25. Billen, G., Lassaletta, L., \& Garnier, J. A vast range of opportunities for feeding the world in 2050: trade-off between diet, $\mathrm{N}$ contamination and international trade. Environ. Res. Lett. https://doi.org/10.1088/1748 9326/10/2/025001 (2015).

26. Msangi, S. \& Batka, M. Major trends in diets and nutrition: a global perspective to 2050. In Frontiers of Economics and Globalization 227-241 (Emerald Group Publishing, 2015)

27. Medek, D. E., Schwartz, J. \& Myers, S. S. Estimated effects of future atmospheric $\mathrm{CO}_{2}$ concentrations on protein intake and the risk of protein deficiency by country and region. Environ. Health Perspect. 125, 87001-87002 (2017)

28. Shutes, L. et al. in Deliverable 7.4: Long-Term Supply, Food and Non-food Demand Drivers, Contrasting Scenarios and Their Impact on FNS-a Report on Long-Term Supply, Food and Non-food Demand Drivers, Contrasting Scenarios and Their Impact on FNS Based on the Toolbox 2050 (ed. Shutes, L.) 3-32 (Wageningen Economic Research, 2017).

29. van Vuuren, D. P. et al. The Representative Concentration Pathways: an overview. Clim. Change 109, 5-31 (2011).

30. van Vuuren, D. P. et al. A new scenario framework for climate change research: scenario matrix architecture. Climatic Change 122, 373-386 (2014)

31. van Vuuren, D. P. et al. The shared socio-economic pathways: trajectories for human development and global environmental change. Glob. Environ. Change 42, 148-152 (2017).

32. O'Neill, B. C. et al. The roads ahead: narratives for shared socioeconomic pathways describing world futures in the 21st century. Glob. Environ. Change 42, 169-180 (2017).

33. Willett, W. et al. Food in the Anthropocene: the EAT-Lancet commission on healthy diets from sustainable food systems. Lancet 393, 447-492 (2019)

34. Leclère, D. et al. Bending the curve of terrestrial biodiversity needs an integrated strategy. Nature 585, 551-556 (2020).

35. FAO How to Feed the World in 2050 (High-Level Expert Forum, 2009).

36. Feed the world: a challenge and an opportunity. The John Deere Journal https://johndeerejournal.com/2015/12/ smallholder-farmers-big-challenges (2015).

37. Carvajal-Yepes, M. et al. A global surveillance system for crop diseases. Science 364, 1237-1239 (2019)

38. Holt-Giménez, E. \& Altieri, M. A. Agroecology, food sovereignty, and the new green revolution. Agroecol. Sustain. Food Syst. 37, 90-102 (2013).

39. Tomlinson, I. Doubling food production to feed the 9 billion: a critical perspective on a key discourse of food security in the UK. J. Rural Stud. 29, 81-90 (2013).

40. Claeys, P. Human Rights and the Food Sovereignty Movement: Reclaiming Control (Routledge, 2015)

41. Grethe, H., Dembele, A. \& Duman, N. How to Feed the World's Growing Billions: Understanding FAO World Food Projections and Their Implications (Heinrich Böll Foundation and WWF Deutschland, 2011).

42. Hunter, M. C., Smith, R. G., Schipanski, M. E., Atwood, L. W. \& Mortensen, D. A. Agriculture in 2050: recalibrating targets for sustainable intensification. BioScience 67, 386-391 (2017).

43. Kearney, J. Food consumption trends and drivers. Phil. Trans. R. Soc. B 365, 2793-2807 (2010).

44. Wirsenius, S., Azar, C. \& Berndes, G. How much land is needed for global food production under scenarios of dietary changes and livestock productivity increases in 2030? Agric. Syst. 103, 621-638 (2010).

45. vonLampe, M. et al. Why do global long-term scenarios for agriculture differ? An overview of the AgMIP global economic model intercomparison. Agric. Econ. 45, 3-20 (2014).

46. Hertel, T. W. \& Baldos, U. L. C. Attaining food and environmental security in an era of globalization. Glob. Environ. Change 41, 195-205 (2016).

47. Robinson, S. et al. Comparing supply-side specifications in models of global agriculture and the food system. Agric. Econ. 45, 21-35 (2014) 
48. Valin, H. et al. The future of food demand: understanding differences in global economic models. Agric. Econ. 45, 51-67 (2014).

49. Risk of Hunger Pandemic as COVID-19 Set to Almost Double Acute Hunger by End of 2020 (World Food Programme, 2020); https://insight.wfp.org/ covid-19-will-almost-double -people-in-acute-hunger-by-end-of-2020-59df0c4a8072

50. Gough, D., Oliver, S. \& Thomas, J. (eds) An Introduction to Systematic Reviews (Sage, 2012); https://doi.org/10.1186/2046-4053-1-28

51. van Vuuren, D. P., Kok, M. T. J., Girod, B., Lucas, P. L. \& de Vries, B. Scenarios in global environmental assessments: key characteristics and lessons for future use. Glob. Environ. Change 22, 884-895 (2012).

52. van Vuuren, D. P. \& Carter, T. R. Climate and socio-economic scenarios for climate change research and assessment: reconciling the new with the old. Climatic Change 122, 415-429 (2014).

53. Dellink, R., van der Mensbrugghe, D. \& Saveyn, B. Shaping baseline scenarios of economic activity with CGE models: introduction to the special issue. J. Glob. Econ. Anal. 5, 1-27 (2020).

54. Börjeson, L., Höjer, M., Dreborg, K.-H., Ekvall, T. \& Finnveden, G. Scenario types and techniques: towards a user's guide. Futures 38, 723-739 (2006).

55. Borenstein, M., Hedges, L. V., Higgins, J. P. T. \& Rothstein, H. R. Introduction to Meta-analysis (John Wiley \& Sons, 2009); https://doi org/10.1002/9780470743386

56. Fox, J. \& Weisberg, S. An R Companion to Applied Regression 3rd edn (Sage, 2019).

57. Bates, D., Mächler, M., Bolker, B. M. \& Walker, S. C. Fitting linear mixed-effects models using lme4. J. Stat. Softw. 67, 1-48 (2015).

58. Kuznetsova, A., Brockhoff, P. B. \& Christensen, R. H. B. lmerTest package: tests in linear mixed effects models. J. Stat. Softw. https://doi.org/10.18637/jss. v082.i13 (2017).

59. Fox, J. \& Weisberg, S. Visualizing fit and lack of fit in complex regression models with predictor effect plots and partial residuals. J. Stat. Softw. 87, 1-27 (2018).

60. Diggle, P. J., Heagarty, P., Liang, K. Y. \& Zeger, S. L. Analysis of Longitudinal Data 2nd edn (Oxford Univ. Press, 2002).

61. Zuur, A. F., Ieno, E. N., Walker, N., Saveliev, A. A. \& Smith, G. M. Mixed Effects Models and Extensions in Ecology with R Statistics for Biology and Health (Springer, 2009); https://doi.org/10.1007/978-0-387-87458-6

62. Nelson, G. C. et al. Food Security, Farming, and Climate Change to 2050: Scenarios, Results, Policy Options (International Food Policy Research Institute, 2010); https://doi.org/10.2499/9780896291867

63. Pardey, P. G., Beddow, J. M., Hurley, T. M., Beatty, T. K. M. \& Eidman, V. R. A bounds analysis of world food futures: global agriculture through to 2050 Aust. J. Agric. Res. Econ. 58, 571-589 (2014).

64. Popp, A. et al. Land-use futures in the Shared Socio-economic Pathways. Glob. Environ. Change 42, 331-345 (2017).

65. Riahi, K. et al. The Shared Socioeconomic Pathways and their energy, land use, and greenhouse gas emissions implications: an overview. Glob. Environ. Change 42, 153-168 (2017).
66. Stehfest, E. et al. Key determinants of global land-use projections. Nat. Commun. https://doi.org/10.1038/s41467-019-09945-w (2019).

67. Hasegawa, T. et al. Risk of increased food insecurity under stringent global climate change mitigation policy. Nat. Clim. Change 8, 699-703 (2018).

68. Gouel, C. \& Guimbard, H. Nutrition Transition and the Structure of Global Food Demand (CEPI, 2017).

69. Bijl, D. L. et al. A physically-based model of long-term food demand. Glob. Environ. Change 45, 47-62 (2017).

70. Food Security Indicators (FAO, 2020); http://www.fao.org/economic/ess/ess-fs/ ess-fadata/en/\#.XiYStoh7mcw

71. R Core Team $R$ : A Language and Environment for Statistical Computing version 4.0.2 https://www.r-project.org/ (2021).

72. Dawson, T. P., Perryman, A. H. \& Osborne, T. M. Modelling impacts of climate change on global food security. Clim. Change 134, 429-440 (2016).

\section{Acknowledgements}

We thank J. Webbink, C. Barrasso and W. de Jong for their support with the systematic literature review. We thank T. Hasegawa, K. Wiebe, D. M. Croz, A. Tabeau and M. von Lampe for making unpublished data available and $\mathrm{H}$. Valin for useful suggestions to improve the paper. This research was funded by a grant from the Stavros Niarchos Foundation as part of the Ethics, Politics, Knowledge and Our Planet's Food Futures project of the Johns Hopkins Global Food Ethics Berman Institute of Bioethics and Policy Program and a grant from Wageningen University and Research. The funders had no role in study design, data collection and analysis, decision to publish or preparation of the manuscript.

\section{Author contributions}

M.v.D. designed the study. M.L.R. organized the systematic literature review. M.v.D. and T.M. prepared the code to process and visualize the data. M.v.D. analysed the data. M.v.D. and Y.S. prepared the manuscript. Y.S. supervised the project.

\section{Competing interests}

The authors declare no competing interests.

\section{Additional information}

Extended data is available for this paper at https://doi.org/10.1038/s43016-021-00322-9. Supplementary information The online version contains supplementary material available at https://doi.org/10.1038/s43016-021-00322-9.

Correspondence and requests for materials should be addressed to M.v.D.

Peer review information Nature Food thanks Shinichiro Fujimori, Alan Dangour and Mike Hamm for their contribution to the peer review of this work.

Reprints and permissions information is available at www.nature.com/reprints.

Publisher's note Springer Nature remains neutral with regard to jurisdictional claims in published maps and institutional affiliations.

(c) The Author(s), under exclusive licence to Springer Nature Limited 2021 
Records identified through database searching

$(n=5237)$

\section{Additional records identified through other sources} $(n=20)$

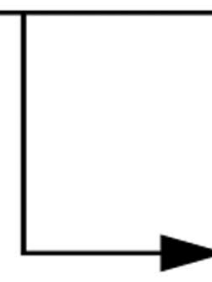

Records after duplicates removed

$(n=3667)$

Duplicates excluded

$(\mathrm{n}=1590)$

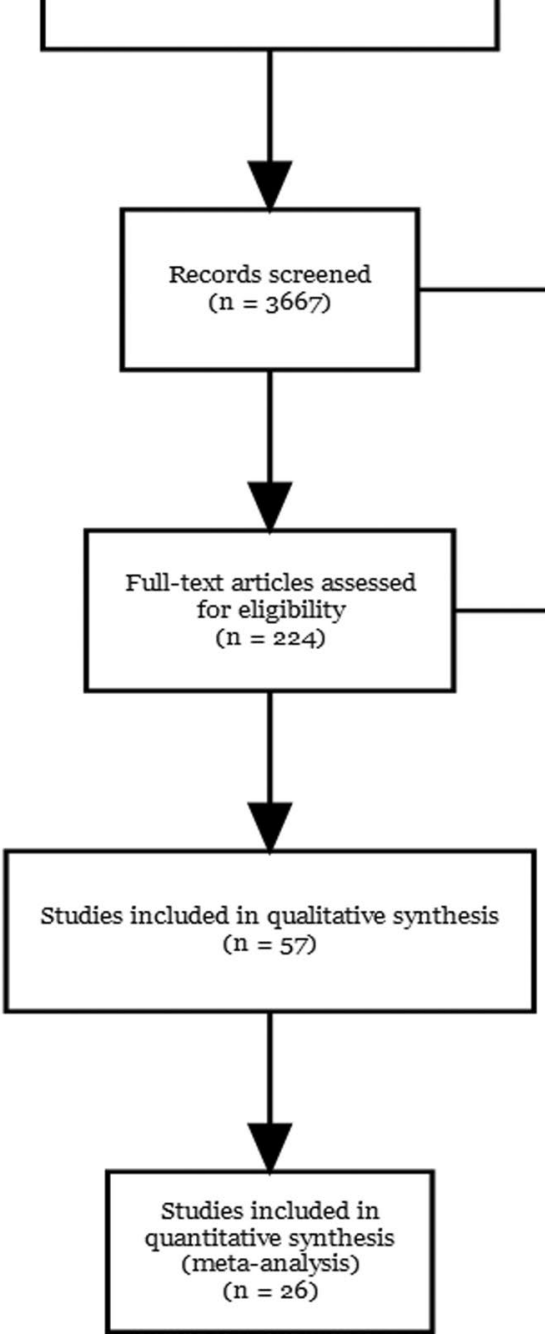

Full-text articles excluded Different topic, no global coverage, time horizon too short, duplicated information $(\mathrm{n}=167)$

Extended Data Fig. 1| Preferred Reporting Items for Systematic Reviews and Meta-Analyses (PRISMA) flow diagram. The diagram shows the different phases of the literature search and screening as well as the number of studies that have been included in the systematic literature review and the number of studies for which data could be extracted for the construction of the Global Food Security Projections Database. See Methods and Supplementary Information for the details of the systematic literature review approach, protocol and selected studies. 


\begin{tabular}{|c|c|}
\hline SSP & Scenario name and storyline \\
\hline SSP1 & $\begin{array}{l}\text { Sustainability } \\
\text { The world shifts gradually, but pervasively, toward a more sustainable path, } \\
\text { emphasizing more inclusive development that respects perceived environmental } \\
\text { boundaries. Management of the global commons slowly improves, educational } \\
\text { and health investments accelerate the demographic transition, and the emphasis } \\
\text { on economic growth shifts toward a broader emphasis on human well-being. } \\
\text { Driven by an increasing commitment to achieving development goals, inequality } \\
\text { is reduced both across and within countries. Consumption is oriented toward low } \\
\text { material growth, low-meat diets and lower resource and energy intensity. }\end{array}$ \\
\hline SSP2 & $\begin{array}{l}\text { Middle of the Road } \\
\text { The world follows a path in which social, economic, and technological trends do } \\
\text { not shift markedly from historical patterns. Development and income growth } \\
\text { proceeds unevenly, with some countries making relatively good progress while } \\
\text { others fall short of expectations. Global and national institutions work toward } \\
\text { but make slow progress in achieving sustainable development goals. } \\
\text { Environmental systems experience degradation, although there are some } \\
\text { improvements and overall the intensity of resource and energy use declines. } \\
\text { Global population growth is moderate and levels off in the second half of the } \\
\text { century. Income inequality persists or improves only slowly and challenges to } \\
\text { reducing vulnerability to societal and environmental changes remain }\end{array}$ \\
\hline SSP3 & $\begin{array}{l}\text { Regional Rivalry } \\
\text { A resurgent nationalism, concerns about competitiveness and security, and } \\
\text { regional conflicts push countries to increasingly focus on domestic or, at most, } \\
\text { regional issues. Policies shift over time to become increasingly oriented toward } \\
\text { national and regional security issues. Countries focus on achieving energy and } \\
\text { food security goals within their own regions at the expense of broader-based } \\
\text { development. Investments in education and technological development decline. } \\
\text { Economic development is slow, consumption is material-intensive, and } \\
\text { inequalities persist or worsen over time. Population growth is low in } \\
\text { industrialized and high in developing countries. A low international priority for } \\
\text { addressing environmental concerns leads to strong environmental degradation in } \\
\text { some regions }\end{array}$ \\
\hline SSP4 & $\begin{array}{l}\text { Inequality } \\
\text { Highly unequal investments in human capital, combined with increasing } \\
\text { disparities in economic opportunity and political power, lead to increasing } \\
\text { inequalities and stratification both across and within countries. Over time, a gap } \\
\text { widens between an internationally-connected society that contributes to } \\
\text { knowledge- and capital-intensive sectors of the global economy, and a fragmented } \\
\text { collection of lower-income, poorly educated societies that work in a labor } \\
\text { intensive, low-tech economy. Social cohesion degrades and conflict and unrest } \\
\text { become increasingly common. Technology development is high in the high-tech } \\
\text { economy and sectors. The globally connected energy sector diversifies, with } \\
\text { investments in both carbon-intensive fuels like coal and unconventional oil, but } \\
\text { also low-carbon energy sources. Environmental policies focus on local issues } \\
\text { around middle and high income areas }\end{array}$ \\
\hline SSP5 & $\begin{array}{l}\text { Fossil-fueled Development } \\
\text { This world places increasing faith in competitive markets, innovation and } \\
\text { participatory societies to produce rapid technological progress and development } \\
\text { of human capital as the path to sustainable development. Global markets are } \\
\text { increasingly integrated. There are also strong investments in health, education, } \\
\text { and institutions to enhance human and social capital. At the same time, the } \\
\text { push for economic and social development is coupled with the exploitation of } \\
\text { abundant fossil fuel resources and the adoption of resource and energy intensive } \\
\text { lifestyles around the world. All these factors lead to rapid growth of the global } \\
\text { economy, while global population peaks and declines in the } 21 \text { st century. Local } \\
\text { environmental problems like air pollution are successfully managed. There is } \\
\text { faith in the ability to effectively manage social and ecological systems, including } \\
\text { by geo-engineering if necessary. }\end{array}$ \\
\hline
\end{tabular}

Extended Data Fig. 2 | Shared Socio-economic Pathways scenario storylines. Source: table 2 in ref. ${ }^{65}$. 
a

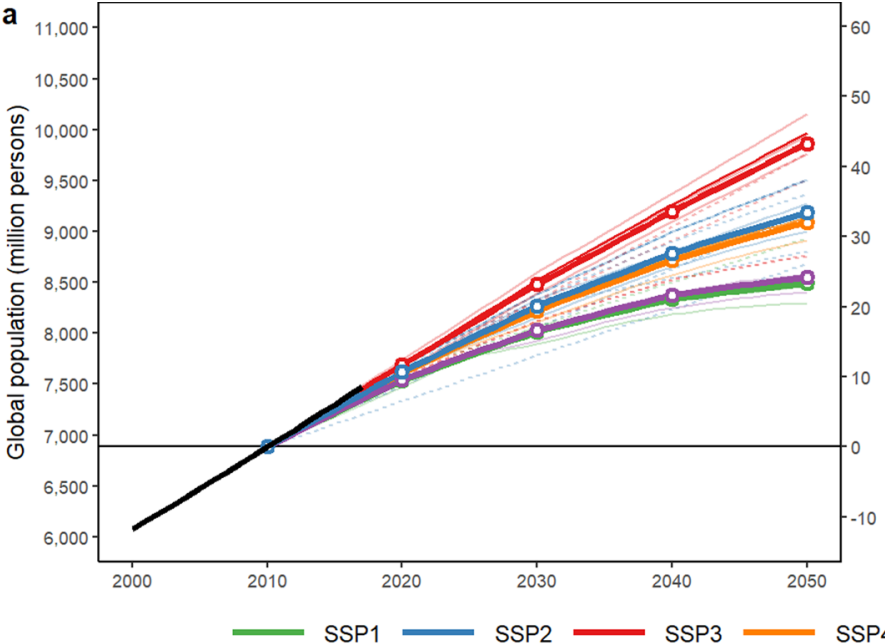

b

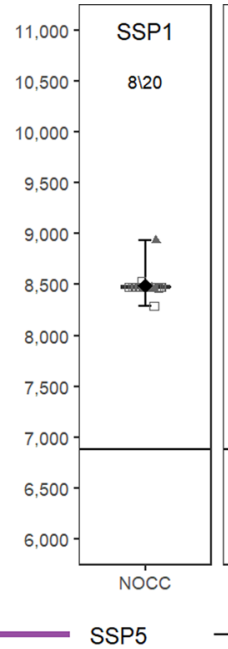

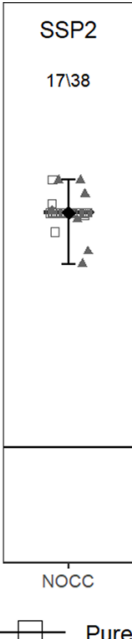

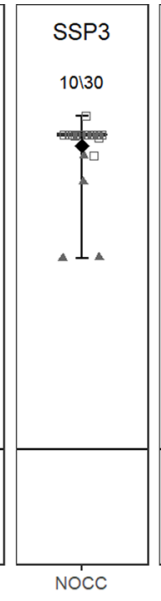

P

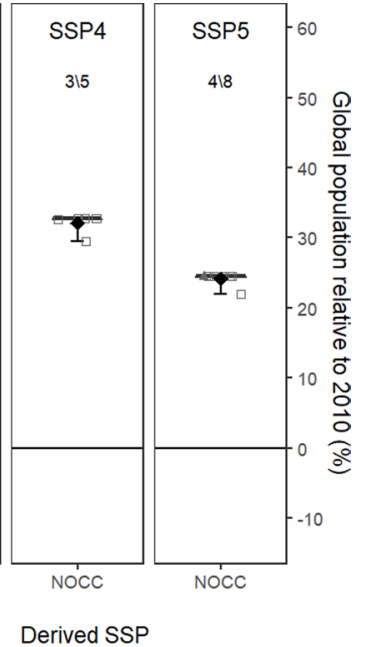

Extended Data Fig. 3 | Population projections for 2010-2050. a, Individual model projections for the SSPs (thin coloured lines), the average for each SSP (the bold coloured lines with circles) and the 3-year average historical trend (bold black line). b, Boxplots for the population projections. The diamond in the boxplot indicates the mean value and the whiskers indicate the maximum and minimum range of observations. SSP Population projections are independent of climate change and therefore only no climate change (NOCC) projections are presented. Projections from the Global Food Security Projections Database. 

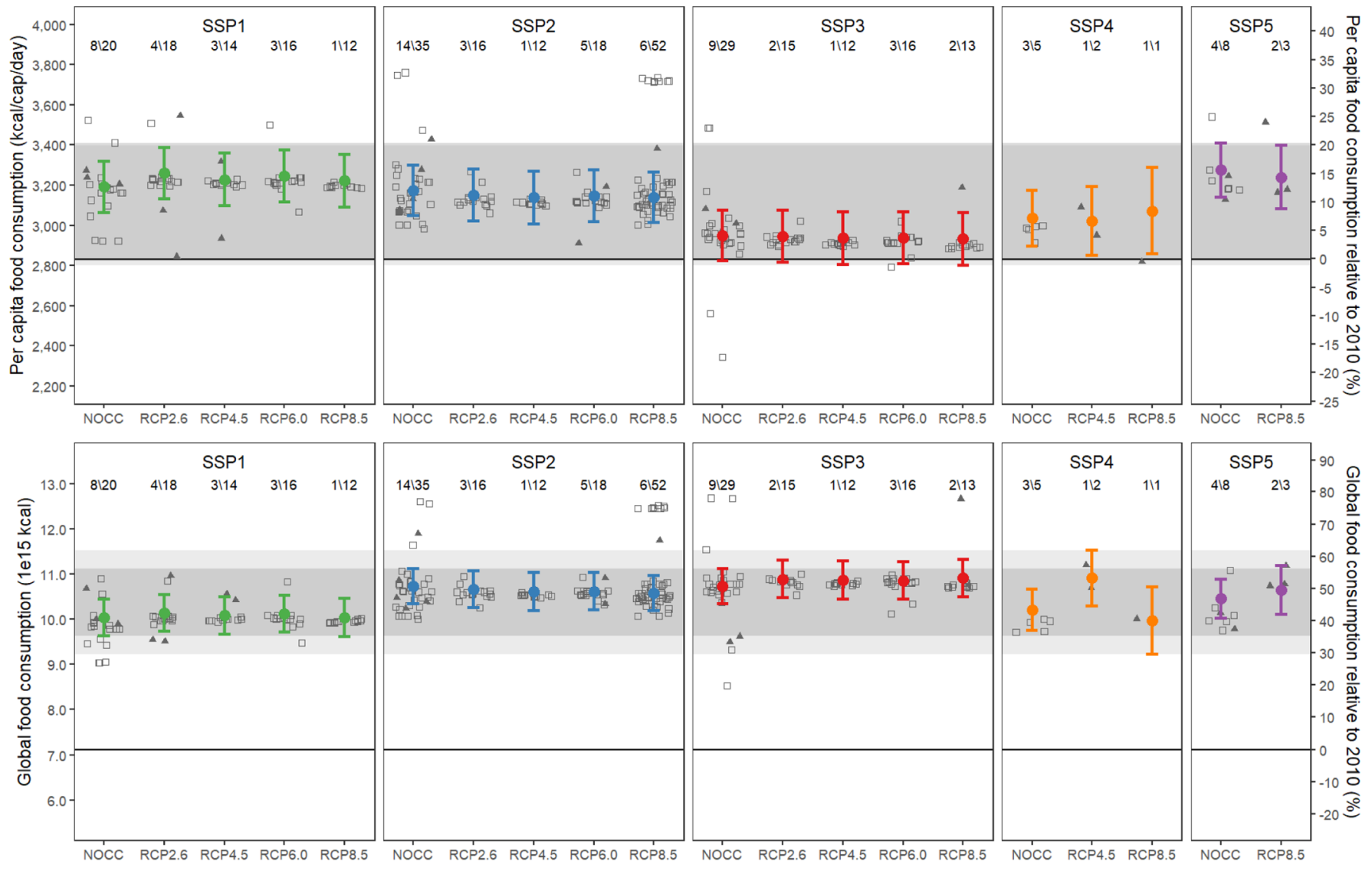

$\longrightarrow$ SSP1 $\multimap$ SSP2 $\multimap$ SSP3 $\longrightarrow$ SSP4 $\longrightarrow$ SSP5

$\square \quad$ Pure SSP

$\Delta \quad$ Derived SSP

Extended Data Fig. 4 | Per capita food consumption (a) and total food consumption (b) projections comparing no climate change (NOCC) with RCP projections for 2050. The dark and light grey shaded areas demarcate the plausible range of projections using the $95 \%$ confidence interval across all NOCC SSP and all RCP SSP projections, respectively. See Fig. 3 for a detailed explanation of the figure elements. 


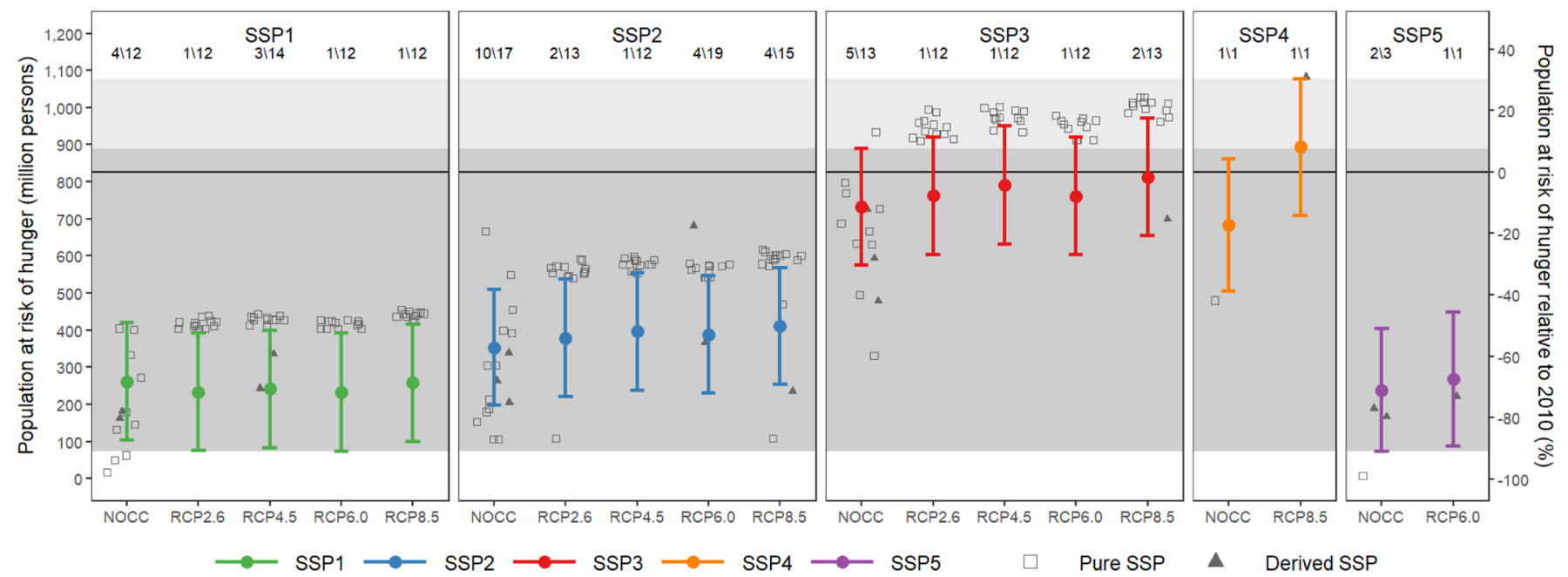

Extended Data Fig. 5 | Population at risk of hunger projections comparing no climate change (NOCC) with RCP projections for 2050. The dark and light grey shaded areas demarcate the plausible range of projections using the $95 \%$ confidence interval across all NOCC SSP and all RCP SSP projections, respectively. See Fig. 4 for a detailed explanation of the figure elements. 


\section{Reporting Summary}

Nature Research wishes to improve the reproducibility of the work that we publish. This form provides structure for consistency and transparency in reporting. For further information on Nature Research policies, see our Editorial Policies and the Editorial Policy Checklist.

\section{Statistics}

For all statistical analyses, confirm that the following items are present in the figure legend, table legend, main text, or Methods section.

n/a Confirmed

$\square \bigotimes$ The exact sample size $(n)$ for each experimental group/condition, given as a discrete number and unit of measurement

Х $\square$ A statement on whether measurements were taken from distinct samples or whether the same sample was measured repeatedly

$\square$ The statistical test(s) used AND whether they are one- or two-sided

$\bigotimes$ Only common tests should be described solely by name; describe more complex techniques in the Methods section.

$\square$ A description of all covariates tested

$\bigotimes \square$ A description of any assumptions or corrections, such as tests of normality and adjustment for multiple comparisons

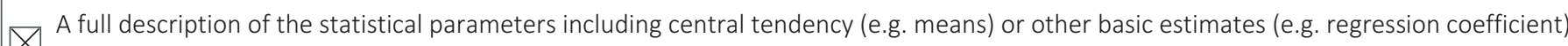

$\bigotimes$ AND variation (e.g. standard deviation) or associated estimates of uncertainty (e.g. confidence intervals)

$\varnothing$ For null hypothesis testing, the test statistic (e.g. $F, t, r$ ) with confidence intervals, effect sizes, degrees of freedom and $P$ value noted

Give P values as exact values whenever suitable.

Х $\square$ For Bayesian analysis, information on the choice of priors and Markov chain Monte Carlo settings

$\square \bigotimes$ For hierarchical and complex designs, identification of the appropriate level for tests and full reporting of outcomes

Х $\square$ Estimates of effect sizes (e.g. Cohen's $d$, Pearson's $r$ ), indicating how they were calculated

Our web collection on statistics for biologists contains articles on many of the points above.

\section{Software and code}

Policy information about availability of computer code

Data collection Data was collected using a systematic review approach. Information from selected articles and reports were structured and coded using the Evidence for Policy and Practice Information and Co-ordinating Centre (EPPI centre, University of London, https://eppi.ioe.ac.uk) tool. Quantitative data on food security projections was harvested and standardized from selected articles where possible. See Methods for details.

Data analysis All analysis and visualization was conducted using R version 4.0.2.

For manuscripts utilizing custom algorithms or software that are central to the research but not yet described in published literature, software must be made available to editors and reviewers. We strongly encourage code deposition in a community repository (e.g. GitHub). See the Nature Research guidelines for submitting code \& software for further information.

\section{Data}

Policy information about availability of data

All manuscripts must include a data availability statement. This statement should provide the following information, where applicable:

- Accession codes, unique identifiers, or web links for publicly available datasets

- A list of figures that have associated raw data

- A description of any restrictions on data availability

All data will be made available before publication by means of a Zenedo repository. All code will be made available before publication by means of a Zenedo repository. The combination of data and code ensures that all results can be reproduced. 


\section{Field-specific reporting}

Please select the one below that is the best fit for your research. If you are not sure, read the appropriate sections before making your selection.

Life sciences

Behavioural \& social sciences

Ecological, evolutionary \& environmental sciences

For a reference copy of the document with all sections, see nature.com/documents/nr-reporting-summary-flat.pdf

\section{Ecological, evolutionary \& environmental sciences study design}

All studies must disclose on these points even when the disclosure is negative.

Study description

To select relevant studies on global food security projections, we followed the guidelines for the qualified application of systematic review by the Evidence for Policy and Practice Information and Co-ordinating Centre (EPPI centre, University of London, https:// eppi.ioe.ac.uk), including the preparation of a research protocol. We also prepared a PRISMA checklist and flowchart. The query of the scientific literature repositories resulted in 3667 studies. After abstract and full text screening, a total of 57 studies were selected to be included in the systematic literature review.

Research sample

For 26 out of the 57 studies that resulted from the systematic literature review of global food security projection studies, we were able to extract quantitative and comparable information on food security projections. The database contains 593 unique projections for food consumption per capita and total food consumption and 358 projections for population at risk of hunger. We used a metaregression model to analyze 317 food consumption and 200 population at risk of hunger baseline projections (see Methods and SI for details of sample selection).

Sampling strategy

The literature search generated a list of potentially relevant studies that were combined and, after removing duplicates, further screened using the EPPI tool, a specialized piece of software for systematic literature reviews. The literature screening was done in two phases. A first selection was made by screening the title and abstract, followed by a full text screening for studies that were identified as being relevant. In case of doubt, the study was evaluated by a second reviewer and, if needed, further discussed by the research team. Quantitative projections were harvested for two indicators: people at risk of hunger and food consumption from the 57 selected studies. This could be done for only 26 studies as the other 31 studies did not provide sufficient detail. The SI of the article describes in detail why data could not be extracted from all studies.

Data collection The research team with support of two research assistants screened all literature and coded the information from the 57 studies. The research team harvested and standardized the projections for the 26 studies for which data was available.

Timing and spatial scale The core of the review was conducted between September 2017 and December 2017. We conducted an additional search mid-2018, using the same protocol, to collect studies that were published in the first half of 2018. Only studies which provide global food security projections were included.

Data exclusions

One observation was considered as an outlier on the basis of IQR criteria and excluded from the meta-regression. See Methods and SI for details.

Reproducibility

All data and code will be publicly available to reproduce the results.

Randomization

Not relevant

Blinding

Not relevant.

Did the study involve field work? $\quad \square$ Yes $\quad$ No

\section{Reporting for specific materials, systems and methods}

We require information from authors about some types of materials, experimental systems and methods used in many studies. Here, indicate whether each material, system or method listed is relevant to your study. If you are not sure if a list item applies to your research, read the appropriate section before selecting a response.

Materials \& experimental systems

n/a Involved in the study

\ $\square$ Antibodies

\ $\square$ Eukaryotic cell lines

Х $\square$ Palaeontology and archaeology

$\bigotimes \square$ Animals and other organisms

$\bigotimes \square$ Human research participants

$\bigotimes \square$ Clinical data

Х

Dual use research of concern

\begin{tabular}{l|l} 
Methods \\
\hline n/a & Involved in the study \\
$\bigotimes$ & $\square$ ChIP-seq \\
$\bigotimes$ & $\square$ Flow cytometry \\
$\bigotimes$ & $\square$ MRI-based neuroimaging
\end{tabular}

